\title{
IMACES IN UROLOCY
}

\section{"FIBROUS PSEUDOTUMOR OF SPERMATIC CORD. A RARE ENTITY"}

Francisco Javier Torres Gomez, Pilar Fernández Machin, Rocío Gonzalez Rodriguez ${ }^{1}$ and Antonia Martínez Moyano?.

Deparment of Urology. TEAPl. Hospital de Alta Resolución de Utrera. Spain.

rological images in the daily clinical practice are sometimes surprising.

We can think that pathological findings in the urological tract are always the same but this is false and the cases published in this section are the proof. We really think that sometimes "an image is enough" and then we report a case of fibrous pseudotumor of the

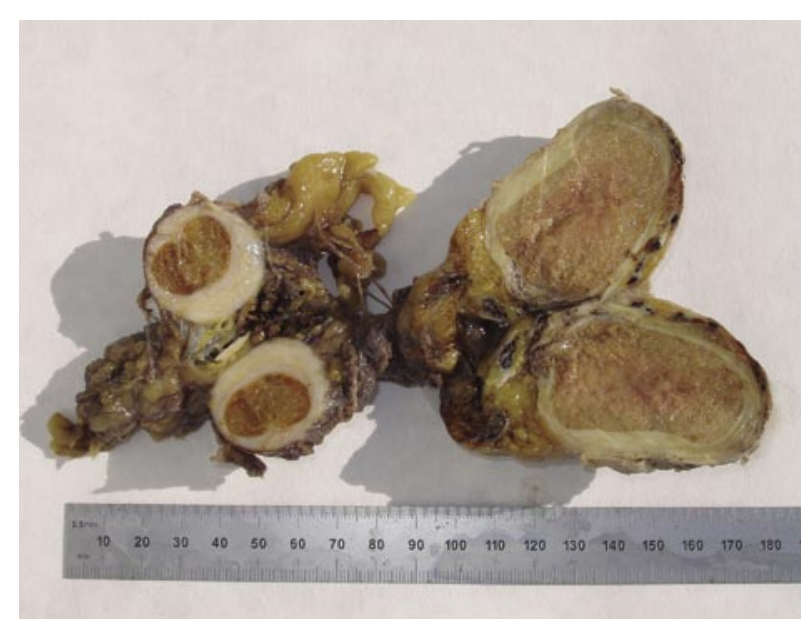

FIGURE 1. Macroscopy

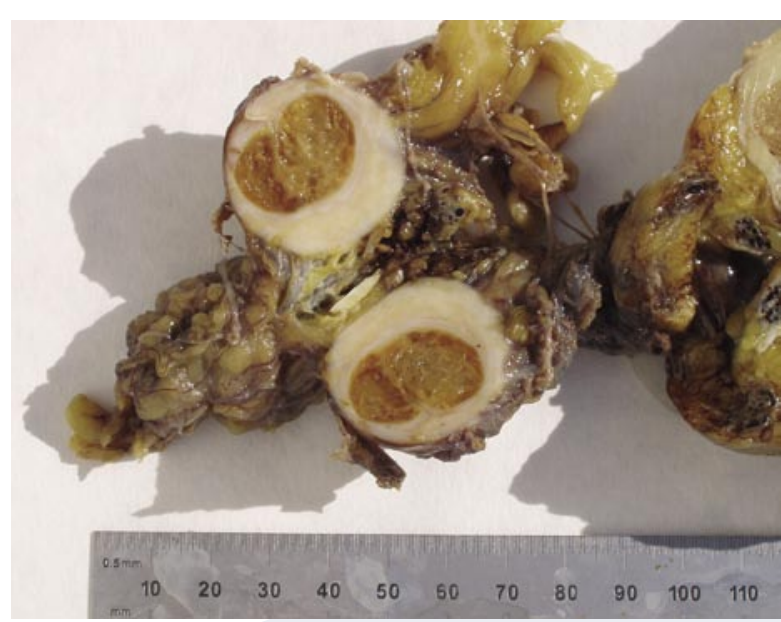

FIGURE 2. Macroscopy. Detail. 
spermatic cord with images like a bivalved egg. Histologic studies let us make a diagnosis refusing other confusing entities by image or surgical criteria. The patient was 78 years old and had an right inguinal mass of $2,2 \mathrm{~cm}$. of

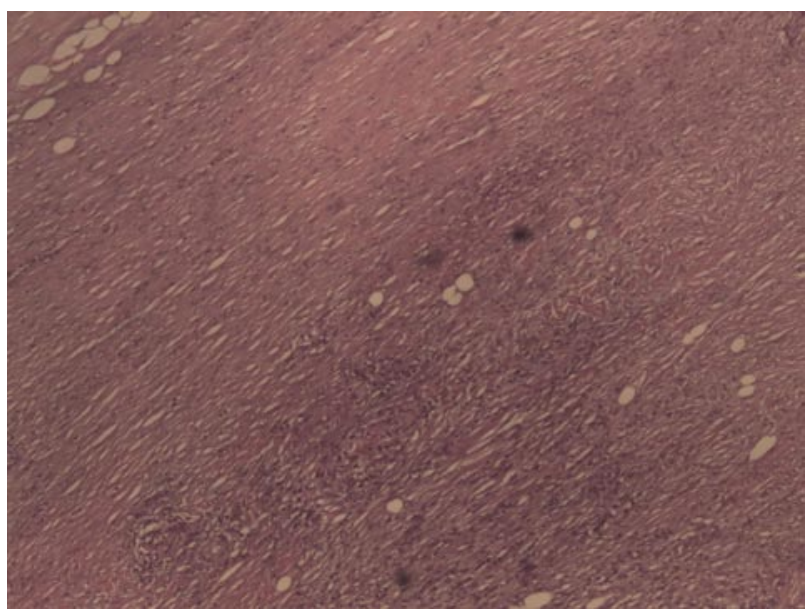
greatest dimension.

FIGURE 3. Histology. HE. 10x.

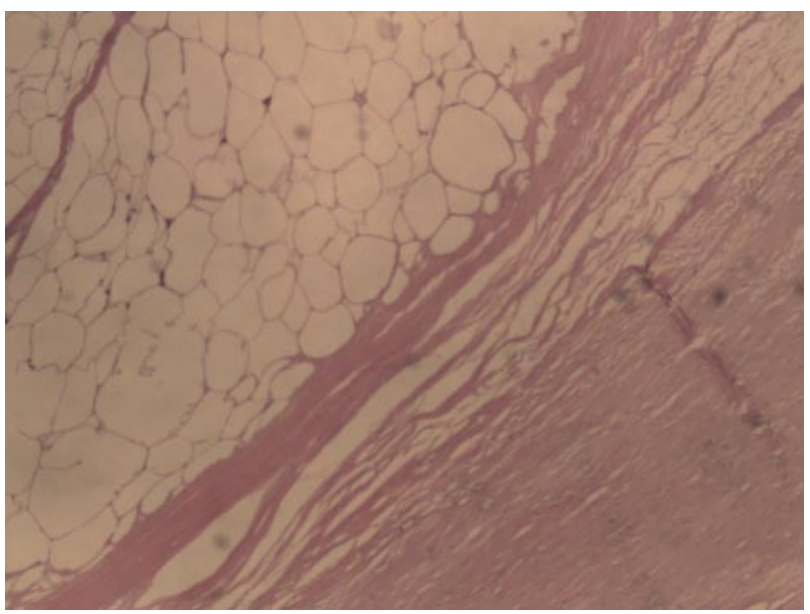

FIGURE 4. Histology. Central core of adipose tissue. HE. 20x.

\section{CORRESPONDENCE}

Francisco Javier Torres Gómez

Hospital de Alta Resolución de Utrera Utrera. Sevilla. (Spain).

javiertorresgomez@yahoo.es 